This item was submitted to Loughborough's Research Repository by the author.

Items in Figshare are protected by copyright, with all rights reserved, unless otherwise indicated.

\title{
How important is the financial sector to price indices in an inflation targeting regime? An empirical analysis of the UK and the US
}

PLEASE CITE THE PUBLISHED VERSION

https://doi.org/10.1007/s11156-016-0578-9

\section{PUBLISHER}

(C) Springer

\section{VERSION}

AM (Accepted Manuscript)

\section{PUBLISHER STATEMENT}

This work is made available according to the conditions of the Creative Commons Attribution-NonCommercialNoDerivatives 4.0 International (CC BY-NC-ND 4.0) licence. Full details of this licence are available at: https://creativecommons.org/licenses/by-nc-nd/4.0/

\section{LICENCE}

CC BY-NC-ND 4.0

\section{REPOSITORY RECORD}

Shah, Imran Hussain, and Ahmad Hassan Ahmad. 2016. "How Important Is the Financial Sector to Price Indices in an Inflation Targeting Regime? an Empirical Analysis of the UK and the US". Loughborough University. https://hdl.handle.net/2134/21219. 


\title{
How important is the Financial Sector to Price Indices in an Inflation Targeting \\ Regime? An Empirical Analysis of the UK and the US
}

\author{
Imran Hussain Shah ${ }^{1}$ \\ Department of Economics \\ University of Bath \\ Claverton Down Rd, \\ Bath, BA2 7AY \\ United Kingdom \\ I.Shah@bath.ac.uk \\ Ahmad Hassan Ahmad \\ School of Business \& Economics \\ Loughborough University \\ Leicestershire, LE 11 3TU \\ United Kingdom \\ A.H.Ahmad@1boro.ac.uk
}

\begin{abstract}
This paper investigates whether there are benefits in terms of higher economic stability from incorporating stock prices into the price index targeted by the central banks. It also looks into the question of whether central banks should use stock prices as a component of the output stability index and how the index can be constructed. An optimization technique is employed to estimate weights for the various sectoral prices. The obtained weights, which depend on sectoral parameters, differ from those used in the construction of the consumer price index, CPI. Using data from the UK and the US, our analysis demonstrates that in comparison to the CPI, our measure of inflation leads to higher output stability. Thus, in an inflation-targeting monetary policy environment, it is important to adopt a broader inflation benchmark than the CPI for the general macroeconomic stability.
\end{abstract}

Keywords: Stock prices, Output Stability Index, Inflation Targeting, Fundamental, Bubbles JEL Classification: D53, E31 E58, G12

\footnotetext{
${ }^{1} \mathrm{We}$ are indebted to the anonymous reviewer and the editor, C.F Lee for the constructive and helpful comments. We are grateful to Wojciech Charemza and Carlos Diaz Vela for assistance in programming. We also acknowledge the helpful comments received from Ricardo Reis, John Hudson and Bruce Morley.
} 


\section{Introduction}

Over the period of last twenty years, central banks of the developed countries have adopted and successfully implemented inflation targeting, IT. The meeting of preset, publicly announced targets for the rate of inflation was crucial for achieving price stability. The period when IT regime was adopted also coincides with the 'great moderation' period during which not only excessive inflation was addressed, but also economic recession was largely absent, until the advent of the 2007-08 financial crisis. Even when the financial crisis forced the central banks to embark on non-conventional policies in the form of quantitative easing, QE, IT still remains at the core of their policy-making decisions. Stabilization of both inflation and output have constitutes a great part of the recent work on monetary policy (e.g. Clarida et al. 1999, 2000 and 2001; Svensson, 2010, 1999a and 1999b; Abo-Zaid and Tuzemen, 2012; Kurozumi, 2012). These authors suggest that central banks should aim at addressing both output volatility and rising inflation ${ }^{2}$.

Policy makers have used variety of methods to minimize detrimental effects of inflation and to contain it at a level that is consistent with the overall objective of economic growth and stability. The benchmark typically used by monetary authorities for inflation targeting is the consumer price index, CPI. However, the CPI, as constructed in many countries, covers only part of the cost of living; asset prices such as real estate and equities are commonly excluded from its computation. The existing literature (e.g. Mankiw and Reis, 2003; Goodhart, 2001) recognizes that the currently employed price indices may not be suitable for conducting monetary policy. The CPI, in particular, does not account for expected inflation (Alchian and Klein, 1973; Kent and Lowe, 1997; Shiratsuka, 1999; Goodhart, 2001).

While the IT regime has been instrumental in handling inflation, there is growing concern that price stability could be impaired in the aftermath of amplified risks from financial instability. Kent and Lowe (1997) argue that asset price increases tend to have, through their influence on the financial structure, small direct but large indirect effects on prices. Following an increase in asset prices, financial institutions expand credit to purchase assets or accept assets as collaterals for loans. This is a clear indication of the importance of choosing an inflation measure to be targeted by the monetary authorities which takes into account the financial sector. Similarly, Blanchard et al. (1993), Cecchetti et al. (2000), and Bordo and Jeanne (2002) argue that substantial consideration should be given to asset price fluctuations as well as to aggregate price movements in order to eliminate misalignments that could result in macroeconomic instability. This is because asset prices form a valuable aid in forecasting static inflation. This strand of the literature maintains that asset prices may be pro-cyclical, with subsequent consequences on the stability of financial markets ${ }^{3}$. Several papers have shown strong relationship between inflation and financial asset returns. These include Laopodis (2010), Al-Khazali and Pyun (2004), Lee (2003) and Kolluri and Wahab (2008).

It is therefore, apparent that financial sector fluctuations impact greatly on the real economy and should, consequently, play a major role in monetary policy decisions. Asset price changes influence expenditure decisions made by households and firms. An increase in the value of an asset makes people better off and inducing further spending. Rising (falling) asset prices increase (decrease) the cost of asset financing, thereby encouraging (discouraging) investment. These observations were borne out of the Japanese experience in

\footnotetext{
${ }^{2}$ In Svensson (2002) for example, the central bank minimizes a quadratic loss function in inflation and output gap.

${ }^{3}$ This view is supported by a number of authors such as Alchian and Klein (1973), Goodhart and Hofmann (2000), Goodhart (2001), and Matalik et al. (2005), Schwartz (2003).
} 
the 1980s, the asset price bubble in the US in the 1990s, and the 2007 sub-prime crisis.

This study assumes that the central bank is committed to an inflation target regime and decides on the most appropriate inflation measure so as to stabilize the real economy. The paper fills in an important gap in the existing literature by attempting to answer the following questions: (i) should the central bank target a price index that incorporates not only the current costs of living but also future prices? (ii) will monetary policy perform better in terms of improving economic stability if the price index that is targeted by the central bank incorporates elements of the financial sector? (iii) how important is price stability (i.e. price index that incorporates aspects of financial sector) in explaining stability in the real economy?

In light of the above, we construct a broad measure of inflation using data from the UK and the US (two countries characterized by predominance of financial markets in their economy) and examine its implications for output stability. Besides using the actual stock prices, we also distinguish between fundamental and bubble components of the stock prices ${ }^{4}$. Thus, for both countries, parameters and weights are estimated for three different combinations of sectoral prices: along with energy, food and other goods prices, we consider successively the actual stock prices, the fundamental component of the stock prices (which should be preferred in case of substantial stock price volatility), and the bubble component of the stock prices.

The main contribution of the paper lies in the construction of a price index that combines the financial sector with traditional CPI components. While we apply the Mankiw and Reis (2003) optimization approach to assign weights to sectoral prices, our weights depend on sectoral parameters that differ from those used in the CPI. The resultant price index is referred to as the 'output stability index', OSI. Central banks that implement an IT regime are interested in indices that stabilize the real economy and produce price stability. To demonstrate the importance of our index, we evaluate the variance of the output gap using both the OSI and the CPI and compute the gain in economic stability achieved by targeting the former rather than the latter as generally the practice.

Our paper differs from that of Mankiw and Reis (2003) in several aspects. First, we undertake a four-sector theoretical analysis of the central bank's problem and derive it's analytic solution. Second, we use asset prices instead of nominal wages. Third, we use generalized method of moments, GMM, to estimate the model parameters as the GMM estimator employs orthogonality conditions that minimize the correlation between idiosyncratic shocks and explanatory variables. Finally, Mankiw and Reis (2003) focus on a theoretical investigation of how heterogeneity affects operation of inflation target in a twosector model in which the associated empirical analysis is only meant to be preliminary. In our case, the centerpiece of the paper is a quantitative application of the approach.

The rest of the paper is organized as follows. Section 2 derives a four-sector analytic solution to the central banks' problem. Section 3 briefly discusses the structures of the UK and the US asset markets, describes the data, and explains the estimation procedures. Section 4 presents our empirical results regarding the model parameters, the optimal weights, and the obtained stability price indices. Section 5 concludes.

\section{The Basic Model: Solving for the Central's Bank Problem}

A central bank that implements IT policy faces a problem of how to choose appropriate weights for a price index that it uses as a measure of inflation, which would lead to minimizing output volatility. Mankiw and Reis (2003) model this problem using several

\footnotetext{
${ }^{4}$ An asset price bubble is that part of asset price movement that remains unexplained.
} 
different sectoral prices with regards to four characteristics ${ }^{5}$ : (i) the budget share and CPI price weighting of various sectors; (ii) changing economic conditions that affect the flexibility of some prices but not others; (iii) prices that are highly responsive to business cycles in some sectors, while less so in others; (iv) comparatively high levels of idiosyncratic shocks in certain sectors.

The existing literature allows for the inclusion of sectoral differences and their implications for monetary policy (Aoki, 2001; Mankiw and Reis, 2002). In addition, Mankiw and Reis (2003) suggest several propositions that can be obtained from these optimal weights to shed light on the nature of the solution. The summary of their propositions is that if the two sectors have different characteristics, then, varying weights are assigned to them, and when two sectors have same sectoral characteristics, equal weights are assigned to them. The results are more appealing when the sectoral characteristics diverge, as this reflects asymmetries in the sectors. Hence, this problem centres on determining optimal weights in the price index to be targeted. If this price index is used as the core measure of inflation by the central bank, it will lead to greater stability in economic condition (output gap). From these, and following in Mankiw and Reis (2003), the central bank's problem can be represented as follows:

$$
\min _{\left\{w_{m}\right\}} \operatorname{Var}\left(z_{t}\right) \quad \text { for } m=1,2, \ldots, M ; \quad t=1,2, . . n
$$

where $z_{t}$ represents the output gap at time $t$ and $w_{m}$ denotes the weight for sectoral $m$. From Mankiw and Reis (2003), the micro-foundation solution for the equilibrium price in sector $m$ can be represented as ${ }^{6}$ :

$$
p_{t, m}^{e}=p_{t}+b_{m} z_{t}+u_{t, m}
$$

where all these variables are in logs. $p_{t, m}^{e}$ is the equilibrium price in sector $m, p_{t}$ is the aggregate price index, $b_{m}$ is the responsiveness of sector $m$ equilibrium price to the business cycle, and $u_{t, m}$ represents idiosyncratic shock to sector $m^{\prime} s$ at time $t$ with variance $\sigma_{m}^{2}$. The parameter $b_{m}$ is the percentage change in the sectoral price caused by the percentage change in output gap. Equation (2) indicates that the optimal relative price in a sector is equal to the magnitude derived from the business cycle and the idiosyncratic shocks. The output gap puts pressure on the marginal costs and on the market powers of firms, and thus shifts the equilibrium price. In the general equilibrium model, changes in output gap influence equilibrium prices through the marginal costs. The response of the relative prices to the changes in business cycle is either countercyclical or procyclical, depending on the nature of the shock. The idiosyncratic relative price shock is referred to as the sector supply shock. The sector supply shock is defined as a sector-specific error term, which captures idiosyncratic price dynamics that are not attributable to the macroeconomic movements (Kaufmann and Lein, 2011).

Equation (2) allows us to assess the responsiveness of sectoral prices with respect to changes in business cycles, and essentially provides an indication of a sector's price changes in relation to the output gap. First, if a sector price is more responsive to the business cycle, it is then expected that the sector's price should have higher optimal, $w_{m}$ in the OSI. This means that the optimal $w_{m}$ increases with an increase in the cyclical sensitivity parameter,

\footnotetext{
${ }^{5}$ See Romer (2012) for details.

${ }^{6}$ See Mankiw and Ress (2003) for the full discussion of the theoretical details.
} 
$b_{m}$. Secondly, the level of noise (as measured by the variance of idiosyncratic shocks) differs between the relative prices. To consider the effects of idiosyncratic shocks on the optimal target weights; the larger the size of shocks in a sector, the lesser the importance that sector's price should receive in the OSI. This means that an increase in the variance of the sectoral shocks, $\sigma_{m}^{2}$ decreases the optimal weight, $w_{m}$. This is because sector prices have low noise (i.e. smaller idiosyncratic shocks as measured by $\sigma_{m}^{2}$ ). A large and unpredictable price change is likely to be accompanied by large idiosyncratic shocks, therefore carrying relatively small information about price trends which in turn leads to a small weight in the target index (Cecchetti et al. 2000). Thirdly, sectoral prices differ on the basis of their weights in the CPI constructed by the Bureau of Statistics. CPI is a measure that consists of average of a basket of consumer goods and services such as food, energy, medical services and education etc. The construction is such that the weights are meant to reflect the relative importance of the goods and services as measured by their contributions to the total spending of households. As weights are based on the amount of money spent by the household on different goods, they are referred to as consumption (expenditure) weights. For sector $m$, the following relationship represents the standard CPI:

$$
p_{t}=\sum_{m=1}^{M} \Phi_{m} p_{t, m}
$$

where $\Phi_{m}$ is the relative percentage (consumption weight) of different sectors in the usual consumer's budget. In all the sectors, the CPI affects the equilibrium prices, demand and costs. A price sector with a comparatively high percentage in the CPI should receive a low weight. This means that an increase in consumption weight reduces the target weight. A price index computed for the attainment of economic stability should also take into account consumption weights. Conversely, in the CPI, relative weights depend on the share of each product in the consumption budget of the ordinary consumer. This illustrates that constructing a price index for determining monetary policy should be different from the one meant for calculating the cost of living. Accordingly, consumption weighting is positively related to sectoral shocks that result in unwanted movements in output and inflation. Through optimal policy making, the central bank should attempt to dampen the effect of these shocks on price equilibrium. For instance, measuring core inflation under IT is achieved by applying relatively less importance to, or permanently excluding, certain components of the price index on the grounds that their prices are considered to be unstable. Since the higher the shock, the more problematic it would be. Therefore, to minimize effect of a shock, a central bank should reduce the weight of the sector in the target price index.

Finally, the model considers that for each time period there are some firms within the economy that gather and update information about the current state of the economy and adjust the optimal path of their future prices. The remaining firms continue using their previous plans and thus set prices based on outdated information (pre-set). This is consistent with models that suggest some sector prices are sluggish while others are flexible. For example Fischer (1977) indicates that this is as a result of some sector prices are set in advance by nominal contracts while Mankiw and Reis (2002) suggest that the sluggishness is due to the fact that some price setters are slow in changing their prices, reflecting lags in information processing. Therefore, these suggest that sector prices consist of a composite of flexible and sluggish prices. The latter are slower in responding to changes in economic conditions. Suppose $\Psi_{m}$ sets prices based on advanced plans, and update information, and 
$\left(1-\Psi_{m}\right)$ denotes proportion of sector $m$ that sets prices based on old information, then the sector price can be given as ${ }^{7}$ :

$$
p_{t, m}=\Psi_{m} p_{t, m}^{e}+\left(1-\Psi_{m}\right) E\left(p_{t, m}^{e}\right)
$$

where $E\left(p_{t, m}^{e}\right)$ denotes the expected value of equilibrium sectoral price in time $t-1$ for time $t$ and the parameter $\Psi_{m}$ measures sluggishness of prices in sector $m$. Low values of $\Psi_{m}$ implies that relative prices do not react immediately to changes in economic conditions, while a high value of $\Psi_{\mathrm{m}}$ (approaching 1) means that the sector's actual price is closer to its equilibrium price level. In case of price sluggishness, smaller values of $\Psi_{m}$ raise the optimal weight $w_{m}$. That is, the less flexible a sector's price is, the more weight that sector's price is given in the OSI. The monetary authorities should target the sluggish price sector as the sluggishness reduces the impact of the output pressure on the sector's price (Aoki, 2001).

\subsection{Optimal Weights for the Output Stability Index}

The solution to the central banks' problem will result into set of optimal weights in a target price index which depends on the sectoral characteristics including $b_{m}, \Phi_{m}, \sigma_{m}^{2}$ and $\Psi_{\mathrm{m}}$. These sectoral characteristics of the parameters are considered as exogenous in the model. The OSI has weighted average of sectoral prices. It is assumed that the central bank maintains a weighted mean of prices at a given level to target inflation, which can be set equal to zero without loss of generality. This can be denoted as:

$$
\bar{p}=\sum_{m=1}^{M} w_{m} p_{t, m}
$$

where $\bar{p}$ is the $O S I$, and $w_{m}$ is the target weight in sector $m$. The sum of the target weights $w_{m}$ is equal to 1 . That is:

$$
\sum_{m=1}^{M} w_{m}=1
$$

The paper derives four sectoral functions addressing the problem faced by the central bank. The following assumptions are used in deriving the four-sector solution: (i) there are only four sectors, called sectors $1,2,3$ and $4(m=1,2,3,4)$. (ii) the sectoral shocks $\left(u_{1}, u_{2}, u_{3}, u_{4}\right)$ are uncorrelated ${ }^{8}$. (iii) the cyclical sensitivity parameters $b_{1}, b_{2}, b_{3}$ and $b_{4}$ are all positive. Equations (2) and (4) are solved to obtain a dynamic that accommodates sector price

\footnotetext{
${ }^{7}$ Theoretical justification for the existence of sluggish and flexible prices within a system stems from the New Keynesian literature.

${ }^{8}$ This assumption is used to obtain a straightforward theoretical solution. However, the empirical analysis uses a more relaxed assumption, and therefore estimates the target weights for sector prices with both correlated and uncorrelated shocks.
} 
deviations represented in equation (8). The variables are taken as deviations from their mean value, such that:

$$
\tilde{z}_{t}=z_{t}-E\left(z_{t}\right), \quad \tilde{p}_{t, m}=p_{t, m}-E\left(p_{t, m}\right), \quad \tilde{p}_{t}=p_{t}-E\left(p_{t}\right) \text { and } \tilde{u}_{t}=u_{t, m}-E\left(u_{t, m}\right)
$$

where tilde $(\sim)$ denotes its deviation form of the variable from its expected value and the expected value of all variable in the deviation form is zero. Therefore, the model is expressed as;

$$
\begin{aligned}
& \tilde{p}_{t, m}=\tilde{p}_{t}+b_{m} \tilde{z}_{t}+\tilde{u}_{t, m} \\
& \tilde{p}_{t, m}=\Psi_{m} \tilde{p}_{t, m}^{e}+\left(1-\Psi_{m}\right) E\left(\tilde{p}_{t, m}^{e}\right), \quad m=1,2,3,4 \\
& \tilde{p}_{t}=\Phi_{1} \tilde{p}_{t, 1}+\Phi_{2} \tilde{p}_{t, 2}+\Phi_{3} \tilde{p}_{t, 3}+\Phi_{4} \tilde{p}_{t, 4} \\
& 0=w_{1} \tilde{p}_{t, 1}+w_{2} \tilde{p}_{t, 2}+w_{3} \tilde{p}_{t, 3}+w_{4} \tilde{p}_{t, 4} \quad, \sum_{m=1}^{M} w_{m} \tilde{p}_{t, m}=0
\end{aligned}
$$

The model considers four sectors $(m=1,2,3,4)$ as stated above, in which the average of the weights is equal to 1 . The model is written as;

$$
\begin{aligned}
& \tilde{p}_{t, m}=\Psi_{m}\left(\tilde{p}_{t}+b_{m} \tilde{z}_{t}+\tilde{u}_{t, m}\right) \\
& \tilde{p}_{t}=\sum_{m=1}^{3} \Phi_{m} \tilde{p}_{t, m}+\left(1-\Phi_{1}-\Phi_{2}-\Phi_{3}\right) \tilde{p}_{t, 4} \\
& 0=\sum_{m=1}^{3} w_{m} \tilde{p}_{t, m}+\left(1-w_{1}-w_{2}-w_{3}\right) \tilde{p}_{t, 4}
\end{aligned}
$$

where , $w_{4}=\left(1-w_{1}-w_{2}-w_{3}\right)$ and $\Phi_{4}=\left(1-\Phi_{1}-\Phi_{2}-\Phi_{3}\right)$. Equation (12) is solved for the equilibrium sectoral prices.

Substituting the equilibrium sectoral prices into equation (14), we solve for variable $\left(\tilde{z}_{t}\right)$ with respect to the parameters $\left(b_{m}, \Phi_{m}, \Psi_{m}, w_{m}\right)$ and the shocks $\left(u_{m}\right)$, taking the conditional expectation of the square of the output gap, conditional upon $I_{t-1}$, where $I_{t}$ is information up to time $t$, given the condition variance. This is because the conditional variance of the output gap, $z_{t}$, is computed with regard to the deviation from the sector prices, $p_{t, m}-E\left(p_{t, m}^{e}\right)^{9}$, assuming the covariances of the shocks are uncorrelated, i.e. $\left[E\left(\tilde{u}_{m}, \tilde{u}_{j}\right)=\sigma_{m j}=0\right\rfloor^{10}$. All these

\footnotetext{
${ }^{9}$ The deviation from the sector prices represents the unexpected shocks as a function of the sector parameters and idiosyncratic shocks.

${ }^{10}$ This condition is to simplify the presentation of otherwise a long mathematical equation. However, in the empirical work, the paper uses both correlated and uncorrelated terms, which have been reported in Tables 2, 3 and 4 as well as in the appendix.
} 
parameters are exogenous and time-specific where they are computed based on the information at $t-1$ for time $t^{11}$. The variance of the output gap is computed based on the following:

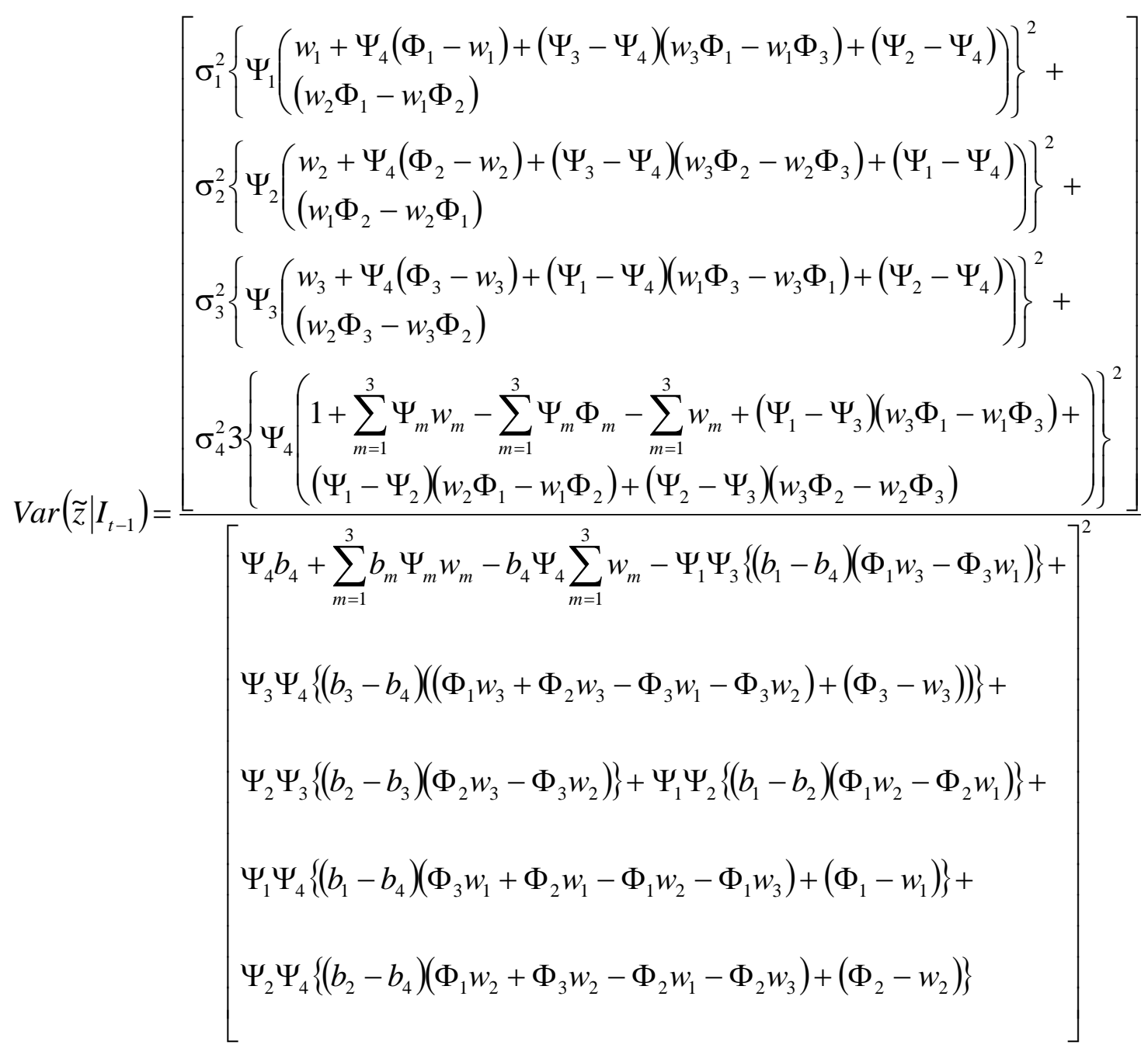

Given the values for these parameters $\left(b_{m}, \Phi_{m}, \Psi_{m}, \sigma_{m}^{2}\right)$, the variance of output gap with respect to the $w_{1}, w_{2}, w_{3}$ and $w_{4}$, is minimised subject to the constraint that the sum of the weights are equal to 1 i.e. $\sum_{m=1}^{M} w_{m}=1$ and probably imposing non-negative constraints $\left(w_{m} \geq 0\right)$. The desired optimal weights can be obtained by meeting these conditions. These optimal target weights are denoted by $w_{1}, w_{2}, w_{3}$ and $w_{4}$ for sectors $1,2,3$ and 4 respectively. These are functions of the sectoral characteristics.

\section{Asset Markets, Data Description and Estimation Procedure}

\footnotetext{
${ }^{11}$ See Mankiw and Reis (2003) for the full discussion.
} 
The data-set consists of quarterly series for the UK and the US covering the period 1981:1 to 2015:3. As discussed in Section 2, the paper is interested in analysing four sector price model: the prices of energy, food, other goods and services and the stock market in order to design a price index for the use of the central bank. In addition, the data-set also contains output gap and CPI for the respective countries. The food, energy and other goods variables are sourced from the OECD database ${ }^{12}$. The study utilizes the weights of different sectors in the typical consumer's budget for both countries, which are taken from the OECD database. Our analysis requires the basket weight for one time period, but for the robustness checks, different periods' consumption weights were also used. However, the results indicate no significant difference. Hodrick-Prescott (HP) filter was used to obtain the output gaps for the countries. Real GDP series were generated by deflating nominal GDP of the countries by using their respective GDP deflator, also sourced from the OECD database. The share (stock) price indices that proxied for the asset prices are taken from the IMF International Financial Statistics Database ${ }^{13}$. Stock indices are used because stock constitutes more than fifty percent of the assets managed and traded in these countries. The stock price variables are the capitalization-weighted index of the top 500 large companies listed stocks in the US (quarterly average of S\&P 500 price index), while for the UK, quarterly average of FTSE all Share price index is used ${ }^{14}$. S\&P is used because of its diversity relative to either Dow Jones or NASDAQ. Similarly, FTSE All Shares is preferred to FTSE 100 as the former is more inclusive than the latter in terms of their coverage.

The UK and the US stock markets are among the largest, with an average market capitalization of about $129 \%$ and $120 \%$ of their GDP between 2000 and 2012, respectively. The high capitalization ratio for both countries reflects the high level of financial development and integration in the economies. Figure 1 shows the size of the stock markets for the two countries for 1990-2012. This contrasts so much with other countries, such as Austria that was just about $17 \%$ for the same period. In addition, they also host very prominent and largest stock exchanges in the world and IT regime has been well established into their monetary policy. The stock markets in these countries have played significant role in determining the state of their economies for about a century (Bordo and Wheelock 2006). Similarly, Hsing (2011) has found that the US stock market index is positively associated with its real GDP.

Figure 1

Asset Markets provide two essential functions as market securities and a price mechanism. The former maintains liquidity, which encourages investors to trade financial assets. The latter on the other hand, determines assets prices that reflect the true investment value of the assets. Generally, stock market is regarded as a good indicator of the economy's performance. Huge downward swings are regarded as sign of a future economic recession while the opposite is seen as signal for future economic growth. This view is backed by the argument that stock prices incorporate future corporate earnings that is related to future output growth. Stock markets affect the economy via two channels. The first channel is through the wealth effects and second channel is that they are seen as avenues through which consumers and corporate organizations express their confidence in the economy and invariably react to monetary policy decisions as reported in Hilliard and Hilliard (2015). This is further buttressed by the argument of PWC (2013) that both the US and the UK stock

\footnotetext{
12 http://stats.oecd.org

${ }^{13} \mathrm{https}$ ://stats.ukdataservice.ac.uk/index.aspx?r=668730\&DataSetCode=IFS\#.

${ }^{14}$ The UK Share Price used is the FTSE All-Share Index, which is a market capitalization weighted index representing the performance of all eligible companies listed on the London Stock Exchange's main market.
} 
markets recorded resilient rises during the fourth quarter of 2013 through to the middle of first quarter of 2013 even in the face of negative growths reported by the countries for the period.

Excessive volatility that characterised stock market prices could make it difficult for central banks to construct a reliable price index that incorporates stock prices ${ }^{15}$. It is in this line that Shiratsuka (1999) opines that CPI is more reliable than stock price indices. However, Goodhart (2001) presents alternative weighting scheme that accommodates stock (asset) price indices. In line with these arguments, this paper adopts an approach similar to that of Anderson and Subbaraman (1996) that decomposes the asset price index into fundamental and non-fundamental (bubble) components ${ }^{16}$. HP-filter technique was used to that end, which distinguishes cyclical behaviour of the asset price from the long run path of the series ${ }^{17}$. If actual stock prices are highly volatile, the fundamental stock prices will be preferred.

As discussed in Section 2, the optimization approach developed to estimate the target weights applied to different sectors in the price index, where the goal of the central bank is to stabilize the real economy. The first step is to assign parameters to the four sectors to estimate the optimum weights ${ }^{18}$. We follow the methodology proposed by Charemza and Shah (2013), which identifies an appropriate method for the estimation of the model. The parameter $\Psi_{\mathrm{m}}$, which measures the degree of price sluggishness, depends on the assumptions that some sector prices are fully flexible while others are sluggish. For completely flexible sectors such as food and energy prices, it is assumed that $\Psi_{\mathrm{m}}=1$. This signifies price setting in these sectors is completely dependent on real economic condition. For sluggish sectors such as other goods and services, and stock prices, it is assumed that $\Psi_{\mathrm{m}}=0.5$. For sensitivity analysis, intervals of $[0.9,1]$ and $[0.45,0.55]^{19}$ for price sluggishness, highly flexible parameters were used and it is repeated by 15000 sampling draws. The model in equation (8) is used to obtain the parameters of $b_{m}$ and ${ }_{m}^{2}$. Equation (8) can be re-written in the following form;

$$
p_{t, m} E\left(p_{t, m}\right)={ }_{m}\left(p_{t} E\left(p_{t}\right)\right)+b_{m} \quad{ }_{m}\left(z_{t} \quad E\left(z_{t}\right)\right)+{ }_{m}\left(u_{t, m} \quad E\left(u_{t, m}\right)\right)
$$

where all the variables are as defined above. The model states that the price disturbance in sector $m$ depends on the aggregate price disturbance, output gap disturbance and a shock. Mankiw and Reis (2003) used an autoregressive, AR, approach to obtain the deviation form for the six disturbance variables. This can be valid provided that all variables are regressed against the same order of lags. However, if the variables are of different lags, which is usually the case, this can be problematic since the variables can have a different order of AR. It also presents potential problems of identification as observed by Mankiw and Reis (2003). This is because sectoral shocks can be correlated with the CPI and the output gap. To address this issue, a vector autoregressive (VAR) model is used to obtain the disturbances from the original data. A VAR model consisting of four sectoral prices, the CPI and the output gap ( $p_{t, m}, p_{t}$ and $z_{t}$ ) was used. The VAR model maintains equality among the variables as it uses the same number of exogenous variables on the right hand side and even the potential

\footnotetext{
${ }^{15}$ See Bernanke and Gertler (1999 and 2001) for details.

${ }^{16}$ Anderson and Subbaraman (1996) separate stock prices into fundamental and speculative components and found that only the former has an impact on investment.

${ }^{17}$ Refer to Hodrick and Prescott (1997) for full discussion of the technique that estimates an unobservable time trend (growth) component of given time series variable.

${ }^{18}$ These target weights depend on the sector parameters.

${ }^{19}$ See Charemza and Shah (2013) for detailed discussion of the methodology.
} 
problem of identification of the model is addressed (Lütkepohl, 2005). In addition, the VAR model has other advantages over the AR model. For example, the VAR as a multivariate system contains more information than a univariate model that only deals with the variable of interest. Secondly, a VAR model does not require specification of which variables are exogenous or endogenous as all variables are, by definition, endogenous. The optimum lags used in the estimation are determined by the use of information criteria ${ }^{20}$. Another concern in obtaining these parameters is that the shocks are likely to be correlated with the CPI. To address this potential problem, the paper formulates appropriate sectoral disturbance variables. These sectoral disturbance variables (rearrange eq. 16) are calculated by dividing the sluggishness parameter in sector $m$ and subtracting from the aggregate price disturbance

$$
\left(\frac{\tilde{p}_{t, m}}{\Psi_{m}}-\tilde{p}_{t}\right)
$$

where the rigidity parameter for each sector is independent from aggregate price ${ }^{21}$. Thus, equation (16) can be re-written as:

$$
\tilde{p}_{t, m}=b_{m} \tilde{z}_{t}+\tilde{u}_{t, m}
$$

Equation (17) illustrates that the disturbance of relative prices depends on the business cycle and the white noise error term. Residuals (disturbance variables) are used as the variables in estimating the equation as prices are often found to possess unit roots. A unit root test indicates that all the variables (disturbances) are stationary, $I(0)$ on levels. This therefore, rules out presence of cointegration between the sector prices and the real GDP ${ }^{22}$. It is assumed that the estimated shocks $\tilde{u}_{t, m}$ are the idiosyncratic ones. The explanatory variable, output gap $\tilde{z}_{t}$ is observed as a disturbance variable. It is likely that idiosyncratic shocks are correlated with non-idiosyncratic components. The model in equation (17) allows the possibility that some or all elements of the explanatory variable may be related with idiosyncratic shocks (composite error). This is the main source of endogeneity for certain explanatory variables in the regression equation. The estimation was undertaken through GMM technique, which is capable of computing the cyclical sensitivity and variance of the idiosyncratic shocks parameters (Ogaki, 1993). In addition, GMM has advantages over maximum likelihood or two-stage least square within the context of this analysis, because the technique allows estimation under restrictions implied by the economic theory and at the same time, it does not require additional distributional assumptions, which may not be part of the theory (Wooldridge, 2001). The explanatory variable (instrument variable) is orthogonal to the disturbance term, $E\left[\tilde{z}_{t}\left(\tilde{p}_{t, m}^{e}-b_{m} \tilde{z}_{t}\right)\right]=0$. The parameter, $b_{m}$ is estimated so that the corresponding sample moments are close to zero.

The parameter of consumption weight $\Phi_{m}$ is the relative percentage of each sector in the CPI. The consumption weight for asset prices is zero. After assigning the parameters to the four sectors these are then substituted into the variance of the output gap in equation (15). Then the variance of the output gap in equation (15) is numerically minimized with respect to $w_{m}$. The paper uses the Newton-Raphson algorithm that is an iterative procedure that calculates maximum likelihood estimates based on the assumptions outlined in 2.1 above. Finally, the relative variance of output gap is estimated from the OSI and the CPI respectively for comparison. This is done in order to check the extent to which the variance

\footnotetext{
${ }^{20}$ We used 1 lag for both countries to estimate the VAR as suggested by the Akaike information criteria.

${ }^{21}$ We use relative sector prices not individual price level. This addresses the issue of non-stationarity.

${ }^{22}$ Results for the unit root test are not reported, but available on request.
} 
of output gap is minimized by targeting the OSI rather than the CPI. The variance of output gap for the OSI is estimated by replacing the four sectors' parameters and optimal weights in the objective function. This procedure first involves estimating all the parameters and optimal weights for each sector. Then, it is substituted in all the parameters in the objective function equation (15). However, output gap variance is estimated for the CPI by evaluating the objective function where the optimal weights are equal to the consumption weights. Additionally, the parameters and consumption weights for asset price are equal to zero because this is not a component of CPI.

\section{Discussion of the Empirical Results}

As discuss in Section 3, optimization techniques were used to compute weights for different sectors in the price index from the perspective that policy maker aims to minimize variability of output gap. Parameters are assigned to the four sectors considered. Sectoral optimum weights depend on the sectoral parameters, which are all exogenous. Table 1 reports the results for the sectoral parameters for the UK and the US. Three regressions were estimated where in the first one stock prices, in addition to energy, food and other goods and services is included. As a robustness check, the second and the third regressions have used fundamental stock prices and bubble prices, respectively instead of stock prices, but including the three components of CPI. The theoretical discussion of the sluggishness parameter, $\Psi$, and the consumption weight, $\Phi$, in Table 1 has been covered in Section 3. The consumption weights represent the weights of different sectors in the CPI. The parameter $b_{m}$, which is the sensitivity of desired prices to the level of economic activity, and $\sigma_{m}^{2}$, the magnitude of idiosyncratic shocks, are computed by the GMM method.

\section{Table 1}

The results reported in Table 1 indicate that the cyclical sensitivity parameter $b_{m}$ for the food sector is larger than most of the other sectors for both countries (except for the financial sector in the UK). But the magnitude of the sectoral shock $\operatorname{Var}(u)$ and consumption weight for the food sector is high. This suggests that food prices are more sensitive to economic activity and large sectoral shocks. This is consistent with the findings of Dubois et al. (2014) that demand structure of some classes of food in the UK and the US varies. The higher sensitivity and lower consumption weights make it a better sector to have a sizeable proportion in the OSI. As mentioned in the theoretical discussion of the model above, the parameter of cyclical sensitivity $b_{m}$ should be pro-cyclical (greater than zero). The parameter value $b_{m}$ for the other goods sector for both countries and the energy sector for the US are zero, which signifies that they are countercyclical. This is consistent with other studies such as Hamilton (2009) who finds that oil prices have a negative relationship with economic activity in the US. The sector shocks $\sigma_{m}^{2}$ and the consumption weight $\Phi_{m}$ for the energy sector are lower than all the other sectors, except for the other goods sector, for both countries. However, the combination of a low sensitivity parameter, $b_{m}$ and a higher value of $\Psi_{m}=1$ suggest that the energy sector is a less desirable sector for use as a component of the OSI. As expected for both countries, stock prices and their components (fundamentals and bubbles) responded significantly to the output gap and large idiosyncratic shocks $\operatorname{Var}(u)$, as is evident in Table 1. This supports the argument of Mankiw and Reis (2003). The UK 
financial sector sensitivity parameter, $b_{m}$, is larger than that of the US, suggesting that the former has a larger financial sector than the latter, relative to their GDP. This is consistent with the data depicted in Figure 1. The large sensitivity to the output gap is due to large cyclical movements in stock prices, as high volatilities and non-systemic movements in stock prices would lead to large idiosyncratic shocks. Therefore, stock prices need to be assigned a relatively higher optimal weight in the OSI despite showing a large variance in the sectoral shocks. These numerical parameter values are substituted into equation (15) which is then minimized with and without the constraints. Table 2 shows the average optimal OSI and CPI weights and output variance from 15,000 optimization experiments for the correlated shocks and Table 3 reports the results for the uncorrelated ones using a similar 15000 optimization experiments. The correlation between the shocks is reported in Appendix A, Tables (A1) and (A2). Three sets of optimal weights for the OSI were computed ${ }^{23}$.

Table 2

The results for the correlated shocks reported in Table 2 are coherent for both countries. The results for the UK show that stock prices are given $20 \%$ weights in the OSI, which is attributable to the combination of the high procyclical sensitivity, zero CPI weight and less flexible parameters. Food and energy sectors receive optimal weights of $58 \%$ and $10 \%$, respectively, in the OSI. Output gap variations are significantly smaller (about 54\%) in the model that used the OSI compared to the one that used the CPI. In addition, stability in real economic activity further increases (about 74\%) when the fundamental component of stock prices is used as a component in the OSI for the UK rather than stock prices. The reduction in the output-gap variations is substantially higher in the OSI relative to the CPI. The explanation lies in the fact that the price index calculated using the fundamental stock price is more reliable than the one that used actual or bubble stock prices. This is because movements in the fundamentals are more systematic and reflect permanent changes. Therefore, it should be given more weight by the policy makers. The results reported in Table 3 , which were obtained from shocks that are uncorrelated, corroborate those in Table 2. The financial sector gets about $37 \%$ of the weight in the OSI and the output gap variance decreases by about $68 \%$. The economic stability obtainable from the OSI is consistent irrespective of whether bubbles or fundamental components of the stock prices are used for the uncorrelated shocks.

Table 3

In the case of correlated shocks, the results for the US show that the other goods sector obtains higher weights, $84 \%$ in the OSI, which is due to the combination of low $\Psi_{m}$ and the small variance of the shocks (see Tables 1 and 2). The combination of high $b_{m}$, low $\Psi_{m}$ and zero consumption weights produce a weight for the stock prices in the OSI of about $1 \%$. Considering that the US is a net oil importing country, the optimal weight for the energy sector is $1 \%$, which is due to the low sectoral shocks and lower consumption weights. The results indicate that the US output gap variance calculated from the OSI is about $74 \%$ smaller than the one from the CPI. These findings suggest that the optimal price index of the central banks could minimize economic instability by giving some weight to asset prices. Although asset prices get a very small optimal weight of about $1 \%$, but recalibrating the weights in the price index would lead to a significant gain in terms of economic stability. Furthermore, both

${ }^{23}$ Empirical estimations have been done using optimization module OPTMUM of GAUSS, version 13. 
the bubble and fundamental components of the stock prices significantly decrease the output gap variance. The reported results in Table 3 for uncorrelated shocks are consistent with those reported in Table 2, but the reduction in the output variance has significantly gone up for both countries.

To check for the robustness of the results, more optimization experiments for different possible combinations were carried out; first, one-time period CPI weights for the year 2011were used as well as using CPI for different years' weights. This is because one might suspect that CPI weights are largely responsible for the high target weight. The result indicates that changing the CPI weights have not significantly affected the optimal weights and output reductions. Secondly, shocks were supposed to be uncorrelated (these are in Table $3)^{24}$ rather than correlated as assumed in the first model, but shocks were allowed to be correlated (Table 2) and it has not affected the results in any significant way. Finally, Table 4 computed the same empirical exercises as in table 2, but it uses the strong assumption that the stock prices are fully flexible, i.e. the parameter $\Psi_{m}$ is equal to 1 for stock prices ${ }^{25}$. Therefore, in all these cases the findings are robust as they consistently show that the OSI still achieves a reduction in output variance for both countries.

Table 4

The findings, in general, signify that rearranging the weights in the price index to include the financial sector in a similar way to that of the OSI would lead to a sizeable gain in terms of output stability in both countries. Over all, the results in Tables 2, 3 and 4 show that the output gap variance reduction is higher in the OSI than in the CPI in both countries. Hence, this suggests that the OSI, as an index targeted by the policy makers would bring about a greater improvement in economic stability than the CPI, which can be better used as a measure of the cost of living. The estimated optimal weights are significant and similar in magnitude as well as consistent across the results reported in Tables 2, 3 and 4. For example, results for the UK confirm that the food and stock (financial) sectors have obtained substantial weights in the OSI across all the experiments. Similarly, results for the US also indicate that the other goods sector has continually received higher weights than the rest of the sectors across all the results reported in the tables. Not only are these optimal weights almost similar in magnitude, but they are all consistently significant across the results. As indicated from the results, the approach adopted by the paper produced consistent results for the two countries, hence supporting the core argument of the paper that the OSI or its variant would be a better target than the CPI. Another thing worth mentioning is that some of the econometric issues highlighted by Mankiw and Reis (2003) such as heterogeneity, endogeneity and autocorrelation have been addressed in this study by using the GMM method and the VAR model.

\section{Figure 2}

Inflation for the two countries is computed using the OSI and the CPI for comparison. These are depicted in Figures 2(a) and 2(b). The computed inflation is defined by the percentage change in the CPI and the OSI over the last year's level in the corresponding quarter. As shown in Figure 2(a), the result for the UK shows large divergence between the

\footnotetext{
${ }^{24}$ See table 3 .

${ }^{25}$ The strong assumption yields results that are fundamentally similar to the ones obtained with the assumption of $\Psi_{m}=0.5$ for stock prices. This corroborates the robustness of the obtained results.
} 
OSI inflation and the headline inflation from the beginning 2000s and the late 2000s. The growth rate of OSI turned negative from 2001 to 2003. It can therefore be stated that monetary policy focusing on the stabilization of the OSI inflation would observe accelerating stock inflation during the late 1990s. Figure (2b) shows that the inflation rates measures by the OSI and the CPI for the US are almost identical and do not fundamentally differ ${ }^{26}$. The main intuition is that OSI and CPI got most of the weight from other good sectors. However, the result shows that resetting the weights in the price index of the US leads to substantial reduction in output variance.

\section{Conclusions}

This paper constructed broad measures of inflation that incorporates stock price indices, using the UK and the US data, and examined whether this measure is superior to the CPI in producing higher output stability in an inflation targeting regime. Our findings suggest that a central bank aiming at economic stability should not only include stock prices in the index of inflation it targets, but should also assign substantial weight to them. For both countries, switching from the CPI to the constructed OSI has resulted in improved real economic stability. The empirical results of the paper have, therefore, addressed the questions of importance of incorporating financial sector in the target price index and to what extent doing that can improve the economic stability, as stated in introductory part of the paper.

An additional attractive feature of our approach is that a carefully constructed OSI can combine different sectoral prices in a way that minimizes the correlation between shocks in the various sectors. Relying on the OSI rather than the CPI is of critical importance to the UK and the US whose economies are highly vulnerable to variations in the stock markets as demonstrated by the paper. For both countries, the reduction in output gap variance is significantly larger, implying that the OSI constitutes a better target for monetary policy implemented via interest rate changes.

The main policy implication of the finding is that for IT to improve macroeconomic stability, interest rate should rise during asset price booms and fall during asset price busts. For instance, in the UK, asset prices rose relative to other prices during the financial crisis of 2007-08. Policy makers could have prevented fluctuations in output by raising interest rate so as to counter the increasing asset prices ${ }^{27}$. However, this should be carried out with caution if financial stability is one of the objectives of the monetary policy.

One could be concerned about using the OSI to maximize stability in countries with relatively small stock markets. But even in this case, there could be benefits from using the OSI as importance of stock markets' contributions to the overall well-being of the global economy has been increasing. This, therefore, comes with monetary policy implications that are relevant to such countries and, therefore, constitutes one of the core contributions of the paper.

One potential debatable issue is the use of the HP Filter to decompose the stock prices into fundamental and bubble components, but the decomposition of the stock prices is not fundamental to the main objectives of the paper. It was meant to show that the decomposed

\footnotetext{
${ }^{26}$ Although both countries implement IT regimes, they do differ in some economic policies and relative importance of the stock market to their GDP. For example, the level of their central banks' independence varies. The Fed has both target and instrument independence while the Bank of England has only instrument independence as the target is defined by the government. In addition, some sectors also differ as Dubois et al. (2014) document, in that some of the countries' commodity demand structures varies, in particular, their food demand structure. This seems credible as it is obvious that their sector prices respond differently to the output gap changes.

${ }^{27}$ In contrast, if asset prices were decreasing faster than the other prices then the central bank could have reacted by cutting down the interest rate.
} 
components of the stock prices may result in differences in the obtained results. But other techniques can be used in future extensions to the research. Secondly, another possible extension would be to include more sectors in the computation of the OSI, such as nominal wages, house prices, tradable and non-tradable goods, etc. However, the latter would come with additional challenges in terms of programming to obtain the necessary solution to the central banks' objective function. 


\section{References}

Abo-Zaid, S. and Tuzemen, D. (2012). Inflation Targeting: A three-decade perspective. Journal of Policy Modeling, 34(5), pp.621-645.

Alchian, A. and Klein, B. (1973). On a Correct Measure of Inflation. Journal of Money, Credit and Banking, 5(1), pp.173-191.

Al-Khazali, O. M. and Pyun, C. S. (2004) Stock Prices and Infalation: New Evidence from the Pacific-Basin Countries, Review of Quantitative Finance and Accounting, 22:2, 123140.

Andersen, M. (1996). Share Prices and Investment. Sydney: Economic Research Dept., Reserve Bank of Australia, Discussion Paper No. 9610.

Aoki, K. (2001). Optimal Monetary Policy Responses to Relative-Price Changes. Journal of Monetary Economics, 48(1), pp.55-80.

Bernanke, B. and Gertler, M. (1999). Monetary Policy and Asset Price Volatility. Economic Review, 84(4), pp.17-51.

Bernanke, B. and Gertler, M. (2001). Should Central Banks Respond to Movements in Asset Prices?, American Economic Review, 91(2), pp.253-257.

Blanchard, O., Rhee, C. and Summers, L. (1993). The Stock Market, Profit, and Investment. The Quarterly Journal of Economics, 108(1), pp.115-136.

Bordo, M. and Jeanne, O. (2002). Monetary Policy and Asset Prices: Does 'Benign Neglect' Make Sense?. International Finance, 5(2), pp.139-164.

Bordo, M. and Wheelock, D. (2006). When do Stock Market Booms Occur? The Macroeconomic and Policy Environments of 20th Century Booms. [St. Louis, Mo.]: Federal Reserve Bank of St. Louis, Working Paper No. 2006-051A.

Cecchetti, S., Genberg, H., Lipsky, J. and Wadhwani, S. (2000). Asset Prices and Central Bank Policy. Geneva: International Center for Monetary and Banking Studies Published by ICMB and the CEPR.

Charemza, W. and Husssain Shah, I. (2013). Stability Price index, Core inflation and Output Volatility. Applied Economics Letters, 20(8), pp.737-741.

Clarida, R., Galí, J. and Gertler, M. (1999). The Science of Monetary Policy: A New Keynesian Perspective. Journal of Economic Literature, 37(4), pp.1661-1707.

Clarida, R., Galí, J. and Gertler, M. (2000). Monetary Policy Rules and Macroeconomic Stability: Evidence and Some Theory. The Quarterly Journal of Economics, 115(1), pp. 147-180.

Clarida, R., Galí, J. and Gertler, M. (2001). Optimal Monetary Policy in Open versus Closed Economies: An Integrated Approach. American Economic Review, 91(2), pp.248-252.

Dubois, P., Griffith, R. and Nevo, A. (2014). Do Prices and Attributes Explain International Differences in Food Purchases?. American Economic Review, 104(3), pp.832-867.

Fischer, S. (1977). Long-Term Contracts, Rational Expectations, and the Optimal Money Supply Rule. Journal of Political Economy, 85(1), pp.191-205. 
Goodhart, C. (2001). What Weight Should be Given to Asset Prices in the Measurement of Inflation?. The Economic Journal, 111(472), pp.335-356.

Goodhart, C. and Hofmann, B. (2000). Do Asset Prices Help to Predict Consumer Price Inflation?. Manchester School, 68(s1), pp.122-140.

Hamilton, J.D. (2009). Causes and Consequences of the Oil Shock of 2007-08. Brookings Papers on Economic Activity, 2009(1), pp.215-261.

Hilliard, J. E. and Hilliard, J. (2015) A Comparison of Rebalanced and Buy and Hold Portfolios: Does Monetary Policy Matter?, Review of Pacific Basin Financial Markets and Policies, 18:1, 155006.

Hodrick, R. and Prescott, E. (1997). Postwar U.S. Business Cycles: An Empirical Investigation. Journal of Money, Credit and Banking, 29(1), pp.1-16.

Hsing, Y. (2011), 'Impacts of Macroeconomic Variables on the U.S. Stock Market Index and Policy Implications', Economics Bulletin, 31(1), pp.883-892.

Kaufmann, D. and Lein-Rupprecht, S. (2011). Sectoral Inflation Dynamics, Idiosyncratic Shocks and Monetary Policy. Zurich: Swiss National Bank, working Paper No. 2011-7.

Kent, C. and Low, P. (1997). Asset-price Bubbles and Monetary Policy. Reserve Bank of Australia, Discussion Paper No. RDP9709.

Kolluri, B. and Wahab, M. (2008) Stock Returns and Expected Inflation: Evidence from an Asymmetric Test Specification, Review of Quantitative Finance and Accounting, 30:4, 371-395

Kurozumi, T. (2012). Sustainability, Flexibility, and Inflation Targeting. Economics Letters, 114(1), pp.80-82.

Laopodis, N. T. (2010) Dynamic Linkages between Monetary Policy and the Stock Market, Review of Quantitative Finance and Accounting, 35:3, 271-293.

Lee, B. (2003) Asset Returns and Inflation in Response to Supply, Monetary and Fiscal Disturbances, Review of Quantitative Finance and Accounting, 21:3, 207-231.

Lütkepohl, H. (1993). Introduction to Multiple Time Series Analysis. Berlin: SpringerVerlag.

Mankiw, N. and Reis, R. (2002). Sticky Information versus Sticky Prices: A Proposal to Replace the New Keynesian Phillips Curve. The Quarterly Journal of Economics, 117(4), pp.1295-1328.

Mankiw, N. and Reis, R. (2003). What Measure of Inflation Should a Central Bank Target?. Journal of the European Economic Association, 1(5), pp.1058-1086.

Matalík, I., Skolkova, M. and Syrovatka, J. (2005). Real Estate Prices and CNB Monetary Policy. Bank for International Settlements, 21, pp.184-96.

Ogaki, M. (1993). Generalized Method of Moments: Econometric Applications. Handbook of Statistics, 11(Eds.), pp.455-488. 
PWC, (2013). Are Stock Markets Reliable Leading Indicators of the Real Economy for the US and the UK?. Available: https://www.pwc.com/et_EE/EE/publications/assets/pub/ stock-markets-and-the-real-economy_l.pdf.

Romer, D. (2012). Advanced Macroeconomics. New York: McGraw-Hill/Irwin.

Schwartz, A. (2003). Asset Price Inflation and Monetary Policy. Atlantic Economic Journal, 31(1), pp.1-14.

Shiratsuka, S. (1999). Asset Price Fluctuation and Price Indices. Monetary and Economic Studies, 17(3), pp. 103-128.

Svensson, L. (1999a). Inflation Targeting as a Monetary Policy Rule. Journal of Monetary Economics, 43(3), pp.607-654.

Svensson, L. (1999b). Inflation Targeting: Some Extensions. Scandinavian Journal of Economics, 101(3), pp.337-361.

Svensson, L. (2002). Inflation Targeting: Should it be Modeled as an Instrument Rule or a Targeting Rule?. European Economic Review, 46(4-5), pp.771-780.

Svensson, L. (2010). Inflation Targeting. Handbook of Monetary Economics, pp.1237-1302.

Wooldridge, J. (2001). Applications of Generalized Method of Moments Estimation. Journal of Economic Perspectives, 15(4), pp.87-100. 
Figure 1: Ratio of Stock Market Capitalization to GDP in UK and US, 1990-2012

$$
\longrightarrow \mathbf{U K} \longrightarrow \mathbf{U S}
$$

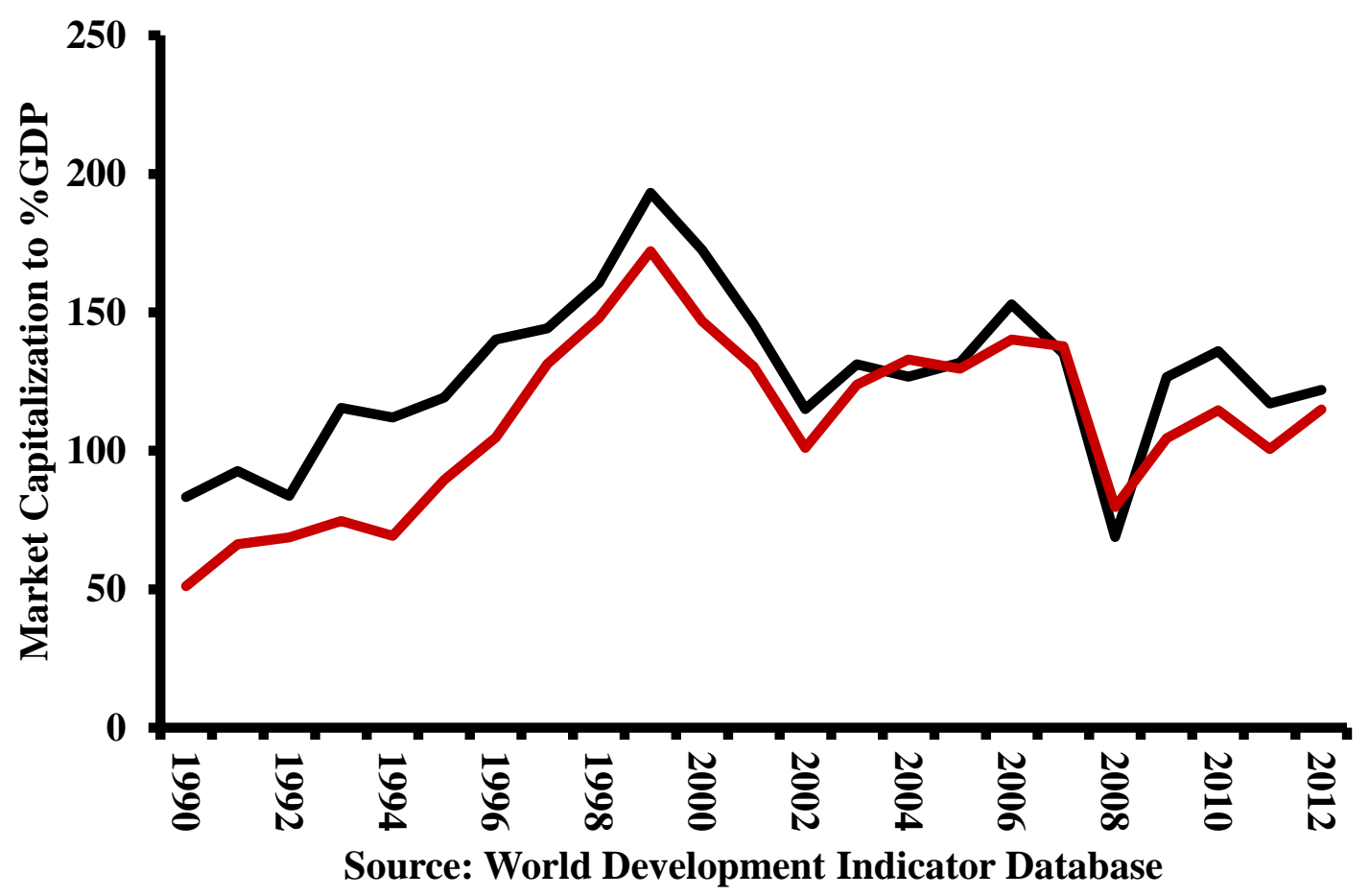


Figure 2:

Comparison of the OSI and the CPI inflation

(2a) UK

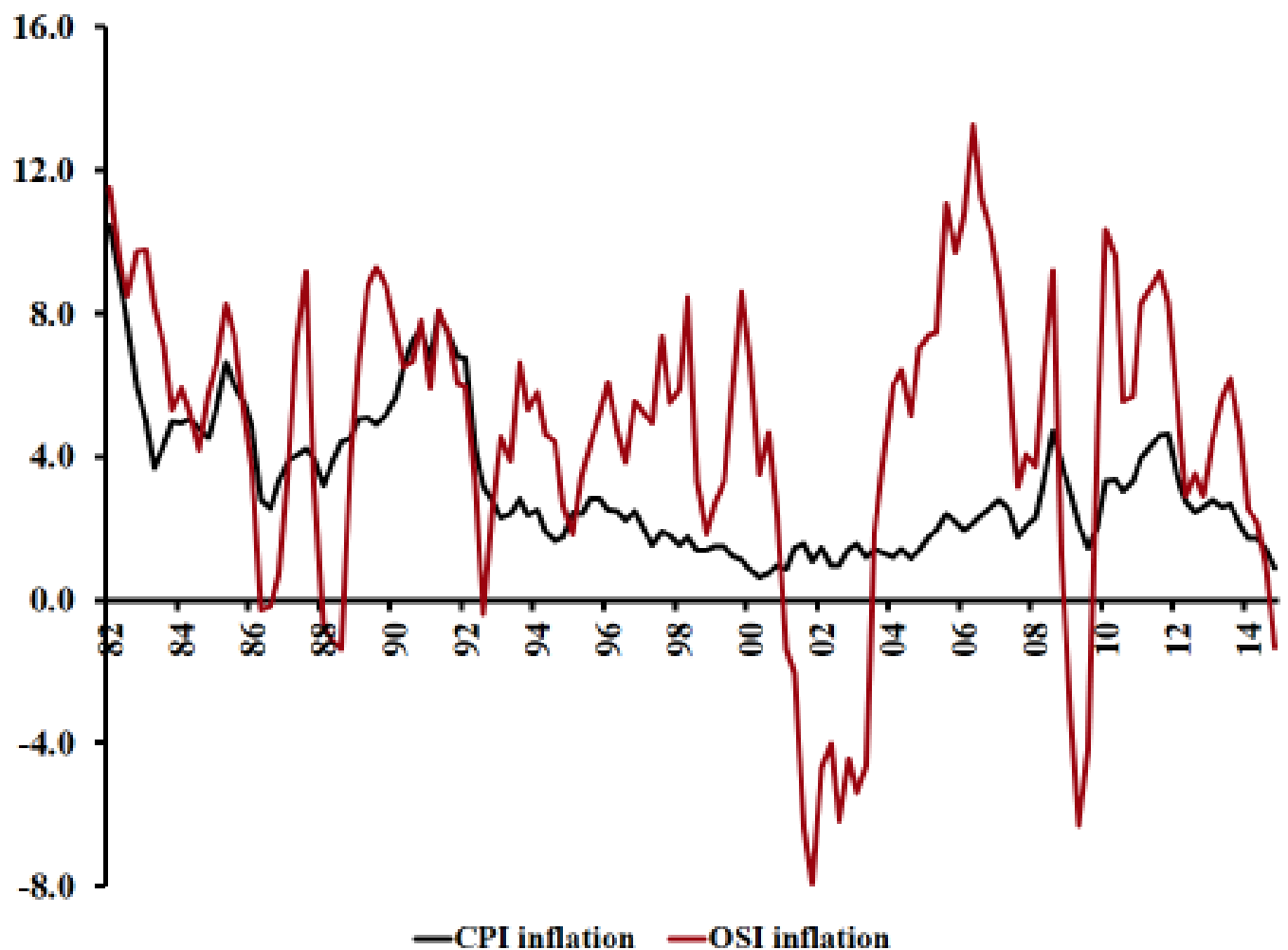

(2b) US

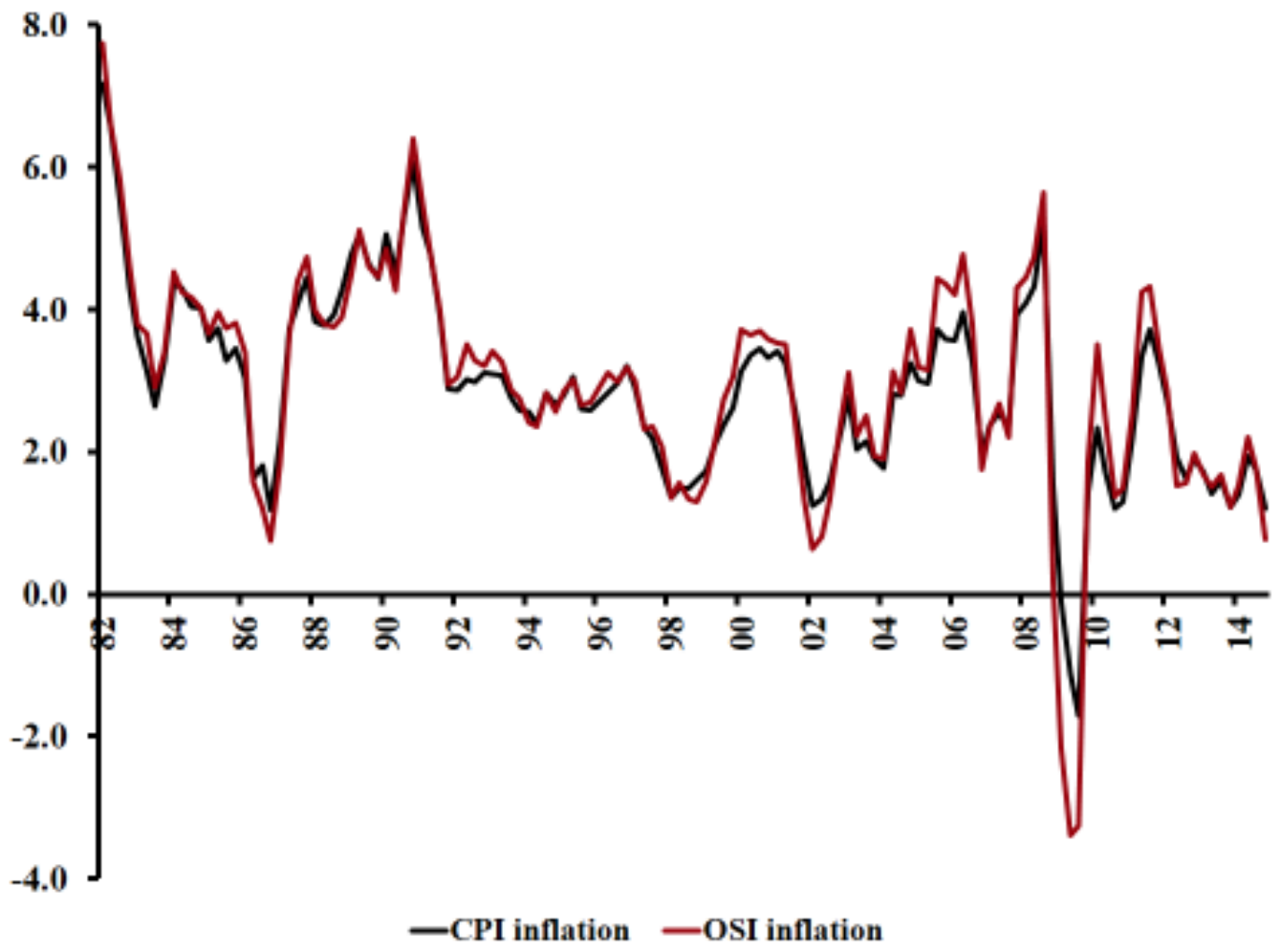


Table 1: Summary of the Sectoral Parameters

\begin{tabular}{|c|c|c|c|c|c|c|c|c|}
\hline \multirow[b]{2}{*}{ Sector } & \multicolumn{4}{|c|}{ UK } & \multicolumn{4}{|c|}{ US } \\
\hline & b & $\operatorname{Var}(\mathrm{u})$ & $\Psi$ & $\Phi$ & b & $\operatorname{Var}(\mathrm{u})$ & $\Psi$ & $\Phi$ \\
\hline Food & 2.57 & 0.000438 & 1.0 & 0.11 & 7.66 & 0.009317 & 1.0 & 0.08 \\
\hline Energy & 0.35 & 0.000085 & 1.0 & 0.10 & 0.00 & 0.000074 & 1.0 & 0.09 \\
\hline Other goods & 0.00 & 0.000043 & 0.5 & 0.79 & 0.00 & 0.000025 & 0.5 & 0.83 \\
\hline Stock & 16.75 & 0.013530 & 0.5 & 0.00 & 4.78 & 0.014620 & 0.5 & 0.00 \\
\hline Fundamental & 10.87 & 0.004011 & 0.5 & 0.00 & 1.22 & 0.005442 & 0.5 & 0.00 \\
\hline Bubble & 3.87 & 0.004875 & 0.5 & 0.00 & 5.89 & 0.002215 & 0.5 & 0.00 \\
\hline
\end{tabular}


Table 2: Weights, CPI and Optimal, from Constrained Optimisation For Mean Lambdas and Sensitivity Standard Errors (Correlated Shocks)

\begin{tabular}{l|llllll}
\hline \hline & \multicolumn{1}{|c}{ Food } & Energy & $\begin{array}{c}\text { Other } \\
\text { goods }\end{array}$ & $\begin{array}{c}\text { Financial } \\
\text { sector }\end{array}$ & $\begin{array}{c}\text { Output } \\
\text { variance }\end{array}$ & $\begin{array}{l}\text { Variance } \\
\text { reduction }\end{array}$ \\
\hline CPI & 0.11 & 0.10 & 0.79 & 0.00 & 0.000094 & 1.00 \\
\hline OSI (sto) & 0.58 & 0.10 & 0.12 & 0.20 & 0.000043 & 2.18 \\
S.E. & $(0.045)$ & $(0.028)$ & $(0.035)$ & $(0.039)$ & \\
OSI (fun) & 0.49 & 0.07 & 0.05 & 0.39 & 0.000024 & 3.89 \\
S.E. & $(0.015)$ & $(0.014)$ & $(0.050)$ & $(0.032)$ \\
OSI (bub) & 0.86 & 0.10 & 0.01 & 0.03 & 0.000034 & 2.77 \\
S.E. & $(0.015)$ & $(0.018)$ & $(0.017)$ & $(0.006)$ \\
\hline \hline
\end{tabular}

Note: Figures in brackets are the standard error (S.E.), sto stands for stock prices, fun denotes fundamental stock prices and bub represents bubble stock prices. 
Table 3: Weights, CPI and Optimal, from Constrained Optimisation For Mean Lambdas and Sensitivity Standard Errors (Uncorrelated Shocks)

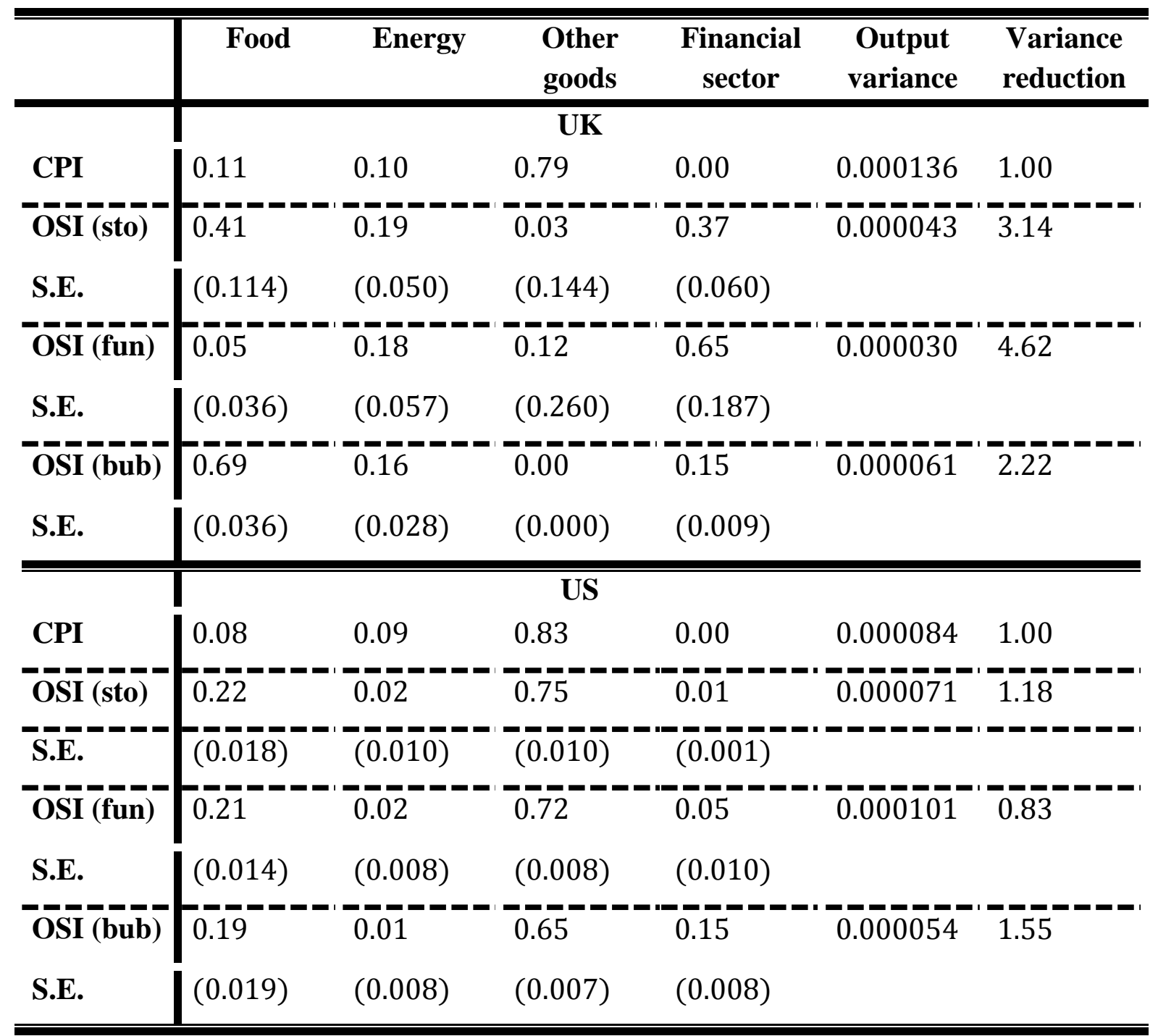

Note: Figures in brackets are the standard error (S.E.), sto stands for stock prices, fun denotes fundamental stock prices and bub represents bubble stock prices. 
Table 4: Weights, CPI and Optimal, from Constrained Optimisation For Mean Lambdas and Sensitivity Standard Errors (Correlated Shocks)

( ${ }_{m}=1$ for financial sector)

\begin{tabular}{|c|c|c|c|c|c|c|}
\hline & Food & Energy & $\begin{array}{l}\text { Other } \\
\text { goods }\end{array}$ & $\begin{array}{c}\text { Financial } \\
\text { sector }\end{array}$ & $\begin{array}{c}\text { Output } \\
\text { variance }\end{array}$ & $\begin{array}{l}\text { Variance } \\
\text { reduction }\end{array}$ \\
\hline \multicolumn{7}{|c|}{ UK } \\
\hline CPI & 0.11 & 0.10 & 0.79 & 0.00 & 0.000106 & 1.00 \\
\hline OSI (sto) & 0.51 & 0.13 & 0.13 & 0.23 & 0.000037 & 2.87 \\
\hline S.E. & $(0.047)$ & $(0.035)$ & $(0.039)$ & \multicolumn{3}{|l|}{$(0.036)$} \\
\hline OSI (fun) & 0.55 & 0.07 & 0.00 & 0.38 & 0.000020 & 5.39 \\
\hline S.E. & $(0.018)$ & $(0.009)$ & $(0.004)$ & \multicolumn{3}{|l|}{$(0.013)$} \\
\hline OSI (bub) & 0.84 & 0.13 & 0.00 & 0.03 & 0.000039 & 2.72 \\
\hline S.E. & $(0.020)$ & $(0.018)$ & $(0.000)$ & \multicolumn{3}{|l|}{$(0.005)$} \\
\hline \multicolumn{7}{|c|}{$\overline{\mathrm{US}}$} \\
\hline CPI & 0.08 & 0.09 & 0.83 & 0.00 & 0.000029 & 1.00 \\
\hline OSI (sto) & $0 . \overline{14}$ & 0.01 & 0.85 & 0.01 & 0.000008 & $\overline{3.66}$ \\
\hline S.E. & $(0.010)$ & $(0.001)$ & $(0.011)$ & \multicolumn{3}{|l|}{$(0.001)$} \\
\hline$\overline{\text { OSI (fun) }}$ & $0 . \overline{14}$ & 0.01 & 0.83 & 0.02 & 0.000012 & $\overline{2.3 \overline{7}}$ \\
\hline S.E. & $(0.009)$ & $(0.001)$ & $(0.011)$ & \multicolumn{3}{|l|}{$(0.004)$} \\
\hline OSI (bub) & $0 . \overline{13}$ & 0.01 & 0.83 & \multirow{2}{*}{\multicolumn{3}{|c|}{$\begin{array}{l}0.03 \\
(0.002)\end{array}$}} \\
\hline S.E. & $(0.015)$ & $(0.001)$ & $(0.015)$ & & & \\
\hline
\end{tabular}

Note: Figures in brackets are the standard error (S.E.), sto stands for stock prices, fun denotes fundamental stock prices and bub represents bubble stock prices. 


\section{Appendix A}

Table A1 - Correlation Matrix of Shock for UK

\begin{tabular}{c|c|c|c|c|}
\hline \hline Sector & Energy & Food & Other goods & Stock \\
\hline Energy & 1.0000 & -0.2817 & -0.4015 & 0.0695 \\
Food & & 1.0000 & -0.1381 & 0.0698 \\
Other goods & & & 1.0000 & -0.0601 \\
Stock & & & & 1.0000 \\
\hline \hline
\end{tabular}

Table A2 - Correlation Matrix of Shock for US

\begin{tabular}{c|c|c|c|c}
\hline \hline Sector & Energy & Food & Other goods & Stock \\
\hline Energy & 1.0000 & -0.5284 & -0.2920 & -0.0679 \\
Food & & 1.0000 & -0.8530 & 0.1359 \\
Other goods & & & 1.0000 & -0.2066 \\
Stock & & & & 1.0000 \\
\hline \hline
\end{tabular}

